
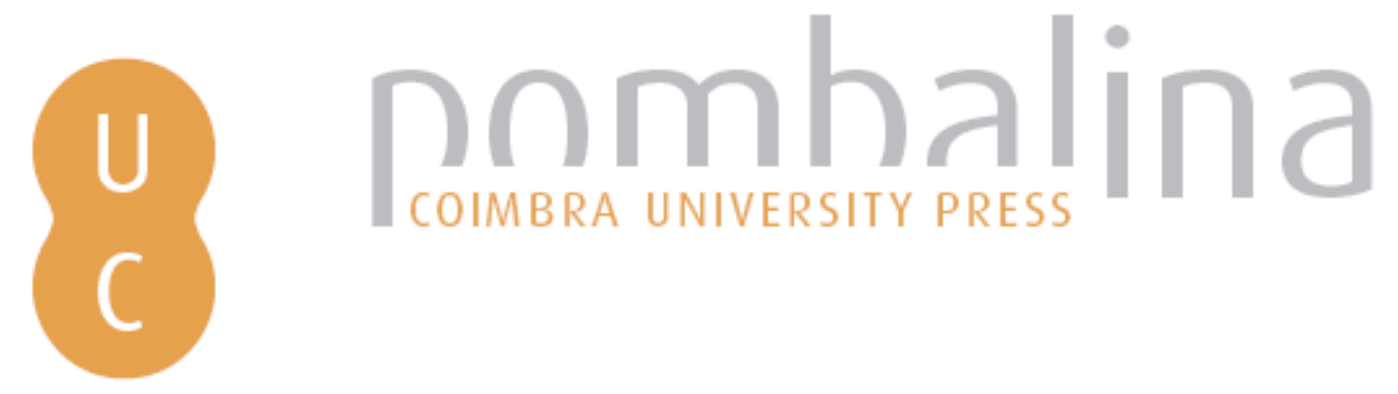

\title{
Avaliação e qualidade das organizações: um estudo de caso: a biblioteca da escola superior de tecnologia do instituto superior politécnico de Viseu
}
Autor(es):
Alves, Maria da Piedade Lopes; Carneiro, Luís Filipe Vieira
Publicado por: Imprensa da Universidade de Coimbra
URL
persistente:
URI:http://hdl.handle.net/10316.2/31958
DOI:
DOI:http://dx.doi.org/10.14195/978-989-26-0869-3_38
Accessed : $\quad$ 26-Apr-2023 13:20:46

A navegação consulta e descarregamento dos títulos inseridos nas Bibliotecas Digitais UC Digitalis, UC Pombalina e UC Impactum, pressupõem a aceitação plena e sem reservas dos Termos e Condições de Uso destas Bibliotecas Digitais, disponíveis em https://digitalis.uc.pt/pt-pt/termos.

Conforme exposto nos referidos Termos e Condições de Uso, o descarregamento de títulos de acesso restrito requer uma licença válida de autorização devendo o utilizador aceder ao(s) documento(s) a partir de um endereço de IP da instituição detentora da supramencionada licença.

Ao utilizador é apenas permitido o descarregamento para uso pessoal, pelo que o emprego do(s) título(s) descarregado(s) para outro fim, designadamente comercial, carece de autorização do respetivo autor ou editor da obra.

Na medida em que todas as obras da UC Digitalis se encontram protegidas pelo Código do Direito de Autor e Direitos Conexos e demais legislação aplicável, toda a cópia, parcial ou total, deste documento, nos casos em que é legalmente admitida, deverá conter ou fazer-se acompanhar por este aviso.

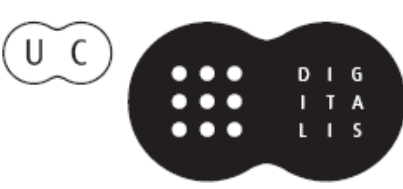


Maria Manuel Borges

Elias Sanz Casado

Coordenação

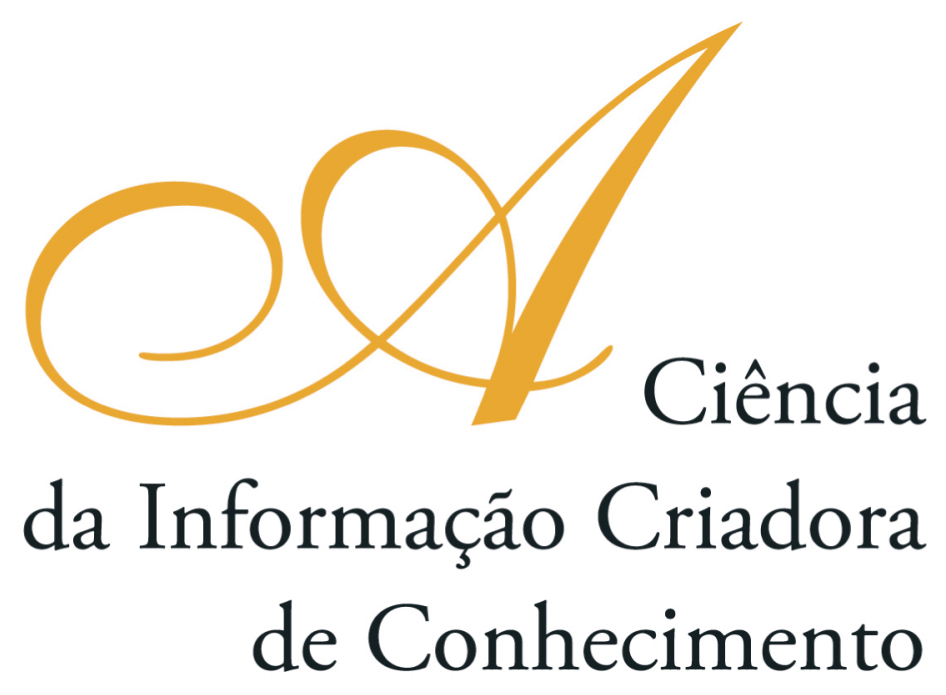

Vol. I I

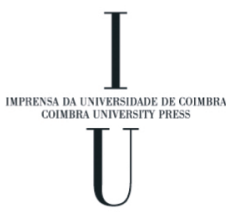

- COImbra 2009 
Maria da Piedade Lopes Alves

Luís Filipe Vieira Carneiro

Instituto Politécnico de Viseu (Portugal)

\section{Introdução}

A avaliação permite-nos conhecer o grau de satisfação dos utilizadores e, através dos resultados obtidos, no caso de se verificar que não correspondem ao que os utilizadores esperam dela, alterar as práticas da organização. A avaliação, mais do que descobrir culpados e puni-los, deve conduzir à determinação correcta dos desvios encontrados e definir as acções necessárias para a sua correcção e evitá-las no futuro. Para o conseguir, é necessário observar o comportamento dos utilizadores/ beneficiários dos serviços que a organização presta a fim de adaptar a sua oferta à evolução das necessidades destes utilizadores. Pretendemos nos debruçar sobre a avaliação de uma organização - A Biblioteca da Escola Superior de Tecnologia do Instituto Politécnico de Viseu -, através do estudo do rendimento e dos conceitos de qualidade e de valor. Procuraremos aportar instrumentos de análise e conclusões empiricamente úteis à avaliação das bibliotecas do Ensino Superior, mas também interessantes para outras organizações. Visando contribuir para esta questão, identificamos as fraquezas/potencialidades e os aspectos críticos que devem ser corrigidos para melhorar a qualidade dos serviços prestados. Tendo por objectivo o tratamento do problema da avaliação do rendimento e da qualidade dos serviços prestados por bibliotecas, procura-se demonstrar alguns dos instrumentos adaptados para a avaliação de serviços desta natureza; e mais especificamente, através deste estudo de caso, pretende-se identificar, entre outros aspectos: 1) os itens mais críticos nos serviços prestados pela biblioteca em questão, segundo a percepção dos utilizadores (professores e alunos); 2) oportunidade de melhoria e acções que possam contribuir para tal, como uma maior divulgação dos serviços desenvolvendo diversas estratégias (por exemplo, um Plano de Marketing).

\section{Objectivos e metodologia}

Inquéritos por questionário

Medir o grau de rendimento da qualidade da Biblioteca da ESTV

Amostra: Aplicação de questionários a todos os elementos da Biblioteca da ESTV (Directora e cinco funcionárias), a 28 professores e a 525 alunos. 


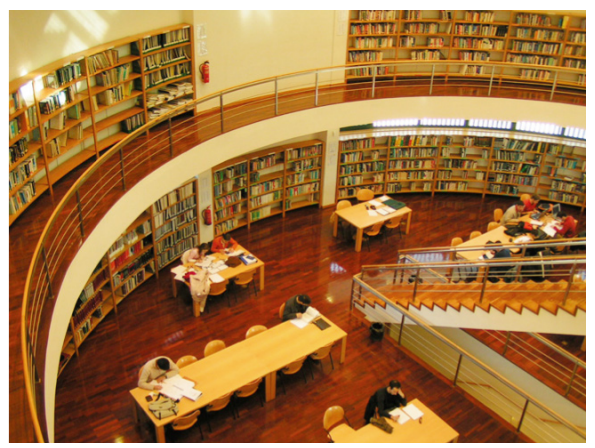

Fig. 1 - Interior da Biblioteca

Fonte: Biblioteca da ESTV

Os questionários foram estudados e permitiram-nos conhecer o grau de satisfação dos seus utilizadores.

Este estudo permitiu-nos identificar os Pontos Fortes e Fracos da referida instituição e, assim, deste modo, elaboramos a Matriz de DAFO.

\section{Resultados e discussão}

Dos seis problemas identificados, e apesar de todos nos parecerem pertinentes, escolhemos, para tratar, A pouca divulgação dos serviços, considerando que se houver um maior conhecimento dos serviços que a Biblioteca disponibiliza, estes serão, certamente, muito mais procurados e, por conseguinte, mais utilizados.

As causas mencionadas foram classificadas do seguinte modo: Recursos Humanos, Recursos Financeiros, Equipamento, Fundos e Métodos. Utilizou-se um Diagrama de causa-efeito (ou de Ishkawa) para explicar devidamente estes itens.

\section{Conclusão}

Para ultrapassar a debilidade detectada, propomos um Plano de Marketing consistindo na elaboraçáo de um CD e de acçóes de formaçáo de utilizadores, ao longo do ano. A avaliaçáo do rendimento e da qualidade dos serviços e recursos de uma biblioteca tem o objectivo fulcral de se obterem elementos essenciais para fundamentar a tomada de decisóes, e deste modo, aproximar os serviços que se prestam ao utilizador. A avaliaçáo deve ser realizada de modo sistemático, estando presente em todo o processo de gestão bibliotecária, que se alimenta com os resultados. A Qualidade, enquanto conjunto das características de um produto ou serviço que conferem à biblioteca aptidão para satisfazer as necessidades explícitas e implícitas de seus utilizadores, deve começar a ser implantada nas instituiçóes, e o resultado é uma mudança na postura. Apesar de ser uma organização sem fins lucrativos, a biblioteca experimenta a necessidade de definir linhas de conduta, proceder a opçóes estratégicas, desenvolver uma política de Marketing e observar criteriosamente os princípios de 
Gestão de Recursos Humanos. A avaliação inscreve-se num processo de planificação que determina como gerir a organização em função das missốes e das prioridades.

É, pois, importante determinar, com regularidade, em que medida responderam às necessidades dos seus utilizadores, em termos de eficácia e pertinência, com o fim de melhorar a 'performance' da organização, neste caso da biblioteca. Para que a avaliação seja um sucesso é fundamental que todos estejam implicados e motivados. A satisfação do utilizador é o objectivo principal de qualquer organização. A qualidade é um tema recorrente nos discursos e transversal a todos os sectores de actividade económico-social. As bibliotecas, pela sua importância, não são excepção, na medida em que procuram caminhos que conduzam à qualidade dos serviços que prestam. De acordo com LAKOS (1999 como citado em MELO, 2004), "as bibliotecas necessitam criar uma cultura organizacional na qual a avaliação é uma componente chave para a compreensão do espaço de encontro, entre o utilizador e a biblioteca". Por isso, dizemos que "AVALIAR É UM VERBO COM FUTURO”.

\section{Referências bibliográficas}

Alves, M. P. G. L. (2007). “Avaliação da Biblioteca do Ensino Superior: Rendimento e Qualidade”. Tese de Doctorado, Faculdad de Tradución y Documentación, Universidad de Salamanca, España.

De la Mano, M. (1998). Propuesta de un sistema de evaluación para bibliotecas universitarias. Revista española de documentación científica, Vol.21 ( $\mathrm{n}^{\circ} 2$ ).

Giappiconi, T. (2001). "Manuel Théorique et pratique d'évaluation des bibliothèques et centres documentaires". Paris: Éditions du cercle de la librairie.

Lakos, A. (1999). The missing ingredient: culture of assessment in libraries. Performance Measurement and Metrics. [Em linha]. pp. 3-8. URL: http://www.aslib.com/pmm/1999/ aug/opinion.pdf [Consultado em 24.07.2009].

Melo, L. B. (2004). Estatísticas e Avaliação da Qualidade e do Desempenho em Bibliotecas e Serviços de Informação: Investigações Recentes e Novos Projectos. $8^{\circ}$ Congresso Nacional de Bibliotecários Arquivistas e Documentalistas, Estoril, 12-14 Maio 2004. 